\title{
Syringomyelia produced by intramedullary fluid injection in dogs
}

\author{
BERNARD WILLIAMS AND R. O. WELLER
}

\author{
From the Royal Infirmary, Hull, and the Department of Neuropathology, Guy's Hospital, London
}

SUMMARY Acute cord cavities have been produced by injection of saline or cerebrospinal fluid into the spinal cords of five beagle dogs. The lesions resemble syringomyelia as seen in the human. The lesions are described and the significance of the findings in supporting a hydrodynamic concept for communicating syringomyelia in the human are discussed.

The pathogenesis of syringomyelia has been the subject of debate since the early part of the nineteenth century. The condition was first described and named by Ollivier (1827) who proposed that it was due to distension of the spinal cord by fluid from within. He injected air into the spinal cord at necropsy and showed that it tracks through the grey matter quite readily. Subsequently it was recognized that syringomyelia cavities may form in association with tumours Poser (1956), but it is those that form without an associated tumour which have aroused more interest among surgeons and pathologists.

Gardner and his co-workers $(1958,1965)$ noted that syringomyelia may be associated with abnormalities at the foramen magnum and they suggested that the syrinx may result from cerebrospinal fluid (CSF) being forced into the central canal of the cord through a communication with the fourth ventricle, and that pulsation of CSF caused by the arterial pulse might be responsible. Williams has suggested $(1970 \mathrm{a}, \mathrm{b})$ that a venous rather than an arterial mechanism may cause progressive distension of the syrinx, and that the term 'communicating syringomyelia' would be useful to differentiate this form of syringomyelia from that caused by invasion by tumours, exudate from tumours, haematomyelia and so on.

The present investigation was undertaken to test the hypothesis that injection of fluid into the spinal cord of dogs would cause a lesion resembling human syringomyelia.

\section{METHODS}

OPERATIVE TECHNIQUE Five beagle dogs between 8.0 and $13.4 \mathrm{~kg}$ were anaesthetized with Immobilon $0.11 \mathrm{ml}$. per $\mathrm{kg}$ and maintained on halothane, nitrous oxide and oxygen during laminectomy of the lower thoracic spine. The dura mater was opened for about $2 \mathrm{~cm}$ of its length and the underlying cord exposed. An injection of about $0.2 \mathrm{ml}$. saline was used to distend the cord before making a small longitudinal incision in the line of the right posterior root entry. Through this, the end of a Holter $\mathrm{C}$ type atrial catheter was introduced and directed upwards within the cord. In the last animal a small $\mathrm{T}$ tube was used so that one end was directed upwards and the other was also inserted within the cord but directed downwards. Muscle was packed around the cord incision, the dura mater was closed over the muscle and the catheter was immobilized with the use of stainless steel wires which were also looped around the spinous processes. The protruding bones and wires were invested with acrylic resin. This was allowed to set over the bones and dura mater in order to limit movement of the exposed portion of the spine.

In three dogs the catheters were exteriorized at a subsequent operation and daily injections of saline were performed for periods varying from three to $\mathbf{5 2}$ days. Injections were not commenced immediately after implantation of the catheter, so that firm scar tissue occurred around the implant, preventing fluid from tracking back along the outside of the catheter.

Injections were commenced with small quantities starting around $0.2 \mathrm{ml}$. and gradually increased, depending partly on the response of the animals at the end of the period of injection. Two animals could receive over $3 \mathrm{ml}$. with little effect towards the end of the injection period (see Table). 
TABLE

DETAILS OF PROCEDURE

\begin{tabular}{|c|c|c|c|c|c|c|}
\hline $\begin{array}{l}\text { Dog } \\
\text { no. }\end{array}$ & $\begin{array}{l}\text { Weight } \\
(\mathrm{kg})\end{array}$ & $\begin{array}{c}\text { Duration between 1st } \\
\text { operation and necropsy } \\
\text { (days) }\end{array}$ & $\begin{array}{l}\text { Injections } \\
\quad(\text { no. })\end{array}$ & $\begin{array}{l}\text { Duration between last } \\
\text { injection and necropsy } \\
\quad \text { (days) }\end{array}$ & $\begin{array}{l}\text { Maximum volume } \\
\text { injected } \\
(\mathrm{ml} .)\end{array}$ & \\
\hline 1 & 13.0 & 120 & 4 & 49 & 0.4 & $\begin{array}{l}\text { Walked with a temporary limp after im- } \\
\text { plantation of catheter. No pain or } \\
\text { neurological deficit produced by cord } \\
\text { injection }\end{array}$ \\
\hline 2 & 13.4 & 125 & 37 & 1 & 3.4 & $\begin{array}{l}\text { Limp after implantation. Sometimes had } \\
\text { pain on injection (Fig. 1) }\end{array}$ \\
\hline 3 & 8.0 & 90 & 52 & 6 & $4 \cdot 0$ & $\begin{array}{l}\text { Appeared to suffer pain on injection, } \\
\text { scoliosis developed. Usually voided } \\
\text { urine after injection (Fig. 2) }\end{array}$ \\
\hline 4 & $10 \cdot 3$ & 30 & 20 & 1 & $\begin{array}{l}5 \text { pumps of } \\
\text { Turner valve }\end{array}$ & $\begin{array}{l}\text { No pain on injection, flexion of the hind } \\
\text { legs, voiding followed by a little stiff- } \\
\text { ness of hind legs (Fig. } 3 \text { ) }\end{array}$ \\
\hline 5 & $12 \cdot 4$ & 18 & 3 & - & $\begin{array}{l}3 \text { pumps of } \\
\text { Turner valve }\end{array}$ & $\begin{array}{l}\text { Severe reaction. Experiment terminated } \\
\text { after three days }\end{array}$ \\
\hline
\end{tabular}
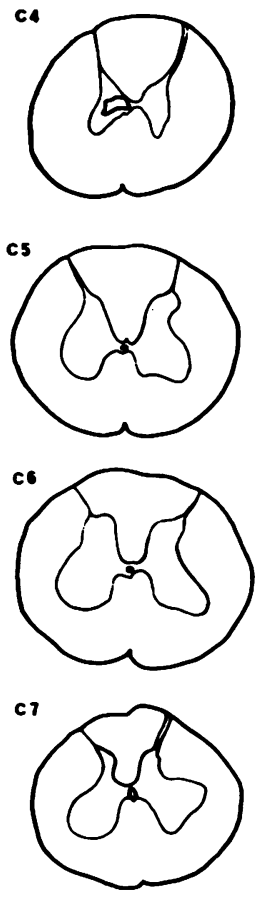
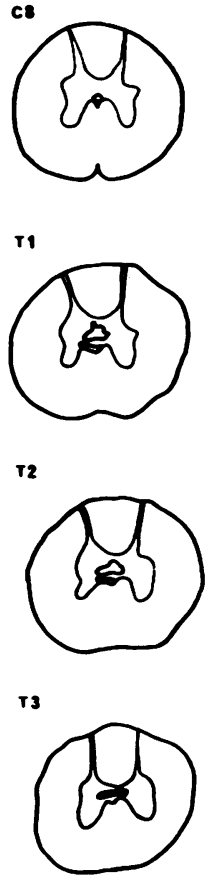

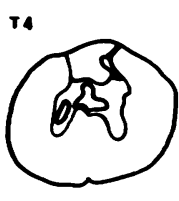

T5
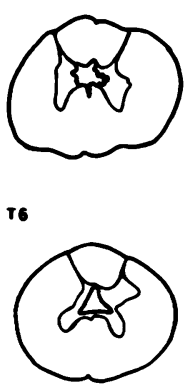

T7

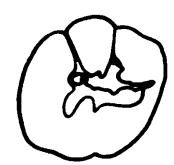

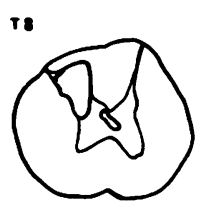

เ9

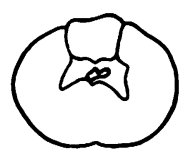

พ 1
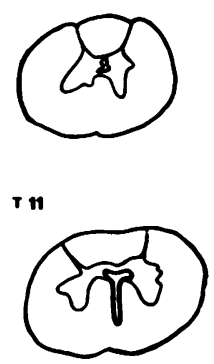

$1 \mathrm{~cm}$

FIG. 1. Cross-sections at affected levels of dog no. 2. The cord disintegrated at T12 segment and below that level was normal. 

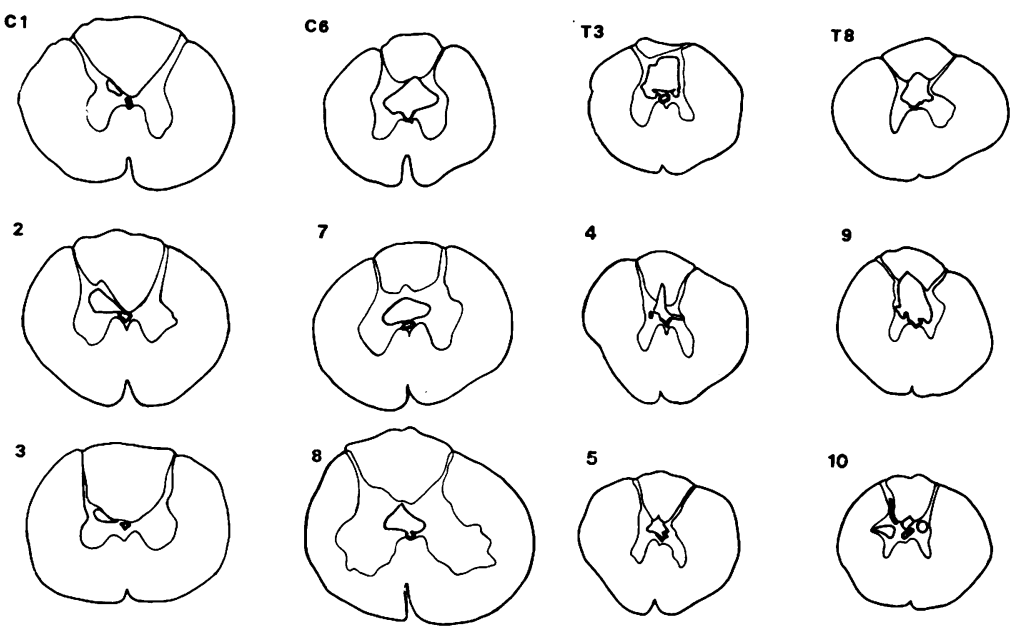

FIG. 2. Cross-sections from dog no. 3 at all levels above $T 12$ segment which was damaged during removal. The cavity at $T 11$ segment showed reaction around the implanted catheter. Below T 12 segment

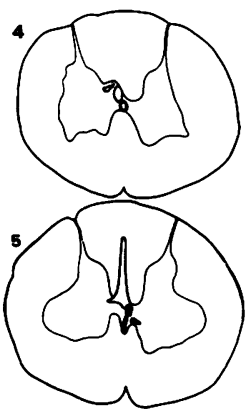

$\mathbf{T}$
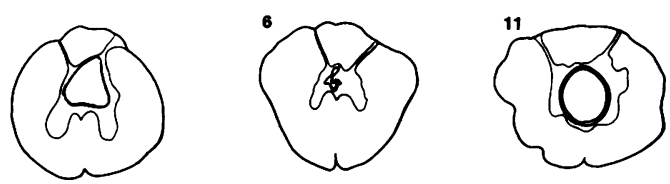
the cord was normal.
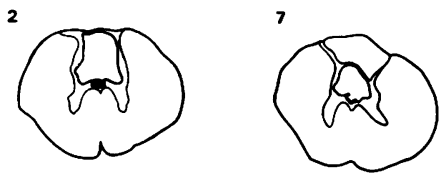

$0.5 \mathrm{~cm}$

TI
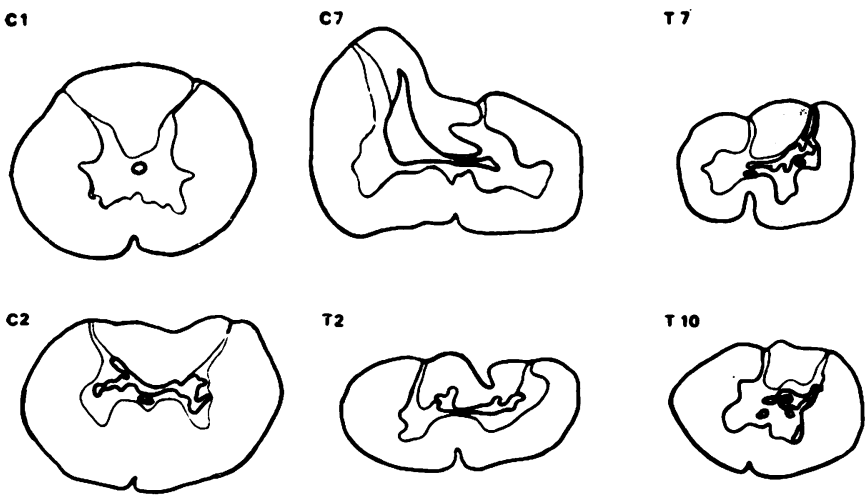

72
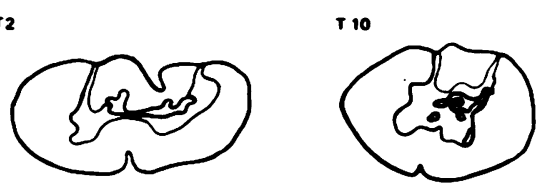

FIG. 3. Representative cross-sections from dog. no. 4. This cavity extended from $C 2$ segment past the level of insertion of the Holter catheter down to $S 2$ segment.

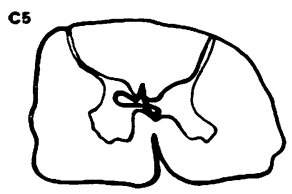

T4
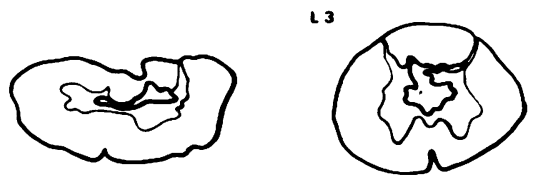

$1 \mathrm{~cm}$

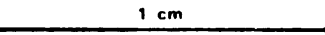


In two other dogs the fourth ventricle was exposed through a suboccipital craniectomy at a later operation and cannulated. A Turner valve (a one way valve similar to a Holter but with a larger volume and no resistance to flow) was located in the folds of skin around the neck permitting cerebrospinal fluid (CSF) to be pumped from the fourth ventricle into the spinal cord by compression of the valve.

Pre-injection anaesthesia was used for animals who gave evidence of pain.

RESPONSE TO INJECTION After implantation of the catheter some neurological deficit was seen in three dogs. Four of the dogs showed some temporary cord dysfunction after the injection of fluid; in three of them the injections sometimes appeared to cause discomfort and in one it appeared to be painful. Progressive neurological deterioration was seen in the last two dogs and the experiment terminated without necropsy on no. 5 .

\section{PATHOLOGY}

PREPARATION OF MATERIAL The first four dogs were injected with pentobarbitone and heparin and perfused with $4 \%$ paraformaldehyde followed by $5 \%$ glutaraldehyde in $0.067 \mathrm{M}$ cacodylate buffer $\mathrm{pH} 7.4$ for 15 minutes. After dissection and removal the spinal cord was further fixed in glutaraldehyde for three hours. Spinal cords were removed within the dura mater and the levels determined from the sites of emergence of roots from the dura mater. The error introduced by this method in the dog is small because of the small degree of cephalic migration of the lower end of the cord compared with the human. The extent of the syrinx was mapped in each case and blocks from all segmental levels were taken for histology and either embedded in paraffin, or post-fixed in osmium tetroxide and embedded in Araldite. Paraffin sections were stained with $\mathrm{H}$ and $\mathrm{E}$, Van Giesen, PTAH, Loyez myelin stain, and Nissl technique. One-micron Araldite sections were stained with $1 \%$ toluidine blue for light microscopy.

Control spinal cords were taken from five dogs without perfusion and fixed in formalin, embedded in paraffin and blocks taken from each segmental level and stained with Azure eosin. One of the dogs used as a control had a coincidental hydrocephalus.

MACROSCOPIC FEATURES In each case the area of implantation of the catheter was firmly fibrosed and the spinal cord was not separable from the dura mater and scar tissue at this level.

The external appearances of the cord away from the site of catheter implantation were normal in each case, except no. 4 where there was a collapse of the

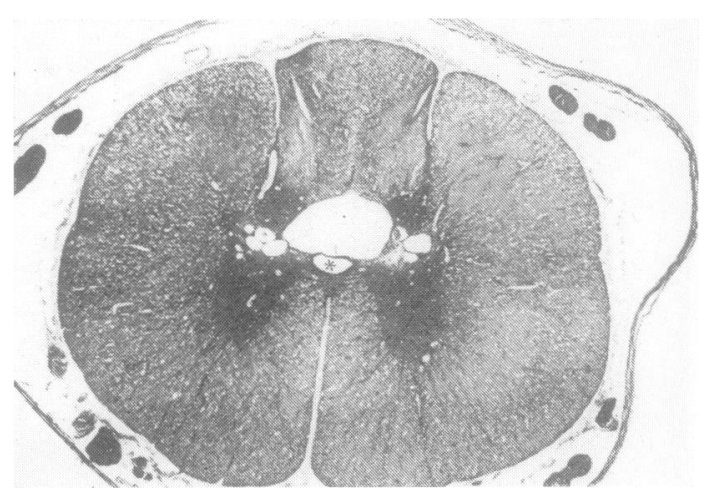

FIG. 4. T.S. spinal cord of dog no. 3 at $C 8$ segment showing a cavity just dorsal to the central canal (*) and several smaller cavities on each side. $H$ and $E$ stain, $\times 8$.

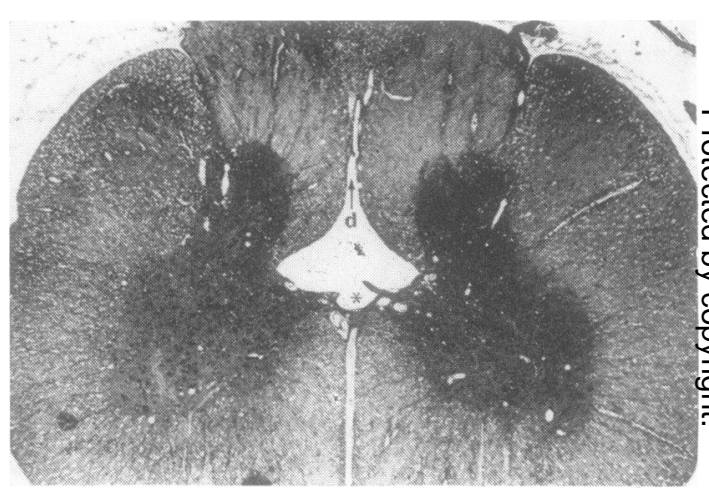

FIG. 5. T.S. spinal cord of dog no. 3 at C 6 segment. $A$ triangular shaped cavity is in continuity with the central canal (*) through the ruptured ependyma and extends into the dorsal median septum (d). $H$ and $E$, stain, $\times 8$.

cord, maximal at $\mathrm{C} .7$ segment. There was no evidence of infection in any of the cases.

Pronounced hydrocephalus with a small aqueduct was found in dog no. 4. The fourth ventricle shared in the dilatation and there was no blockage of the outlets of the fourth ventricle at either operation or necropsy. The brain appeared to be normal in the other cases. The cavities and central canals in dogs nos. 2, 3, and 4 are shown in Figs. 1-3 which have been prepared by tracing projected sections.

HISTOLOGY Despite the variation in the macroscopic appearances, the type of histological changes seen in 


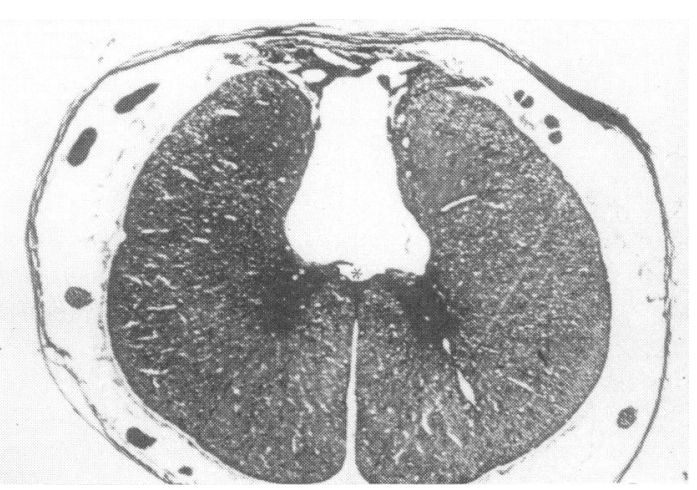

FIG. 6. T.S. spinal cord of dog no. 3 at T 2 segment showing a large cavity disrupting the dorsal aspect of the cord. The ependyma around the central canal (*) is ruptured. $H$ and $E$ stain, $\times 8$.

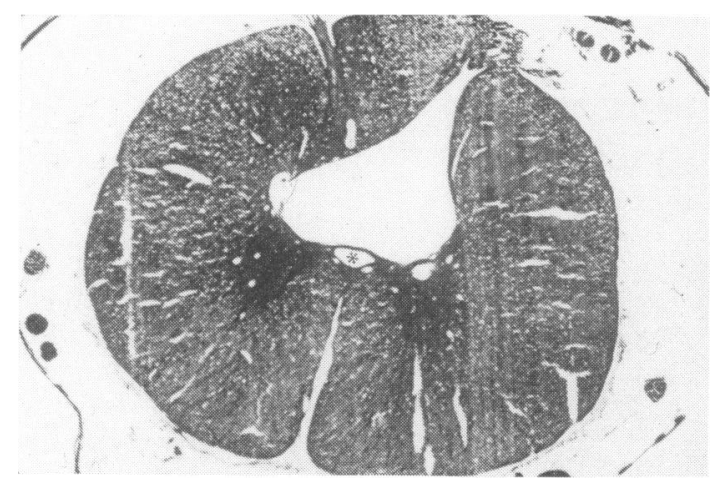

FIG. 7. T.S. spinal cord of dog no. 3 at $T 1$ segment. $A$ cavity has extended towards one dorsal root. The central canal (*) is intact. $H$ and $E$ stain, $\times 8$.

the spinal cords is very similar in all the animals; the four dogs will therefore be described together.

FORM AND LOCATION OF SYRINGOMYELIC CAVITIES The syrinx is usually situated between the posterior horns and dorsal to the grey commissure. Very rarely the syrinx extends ventrally into the median fissure. When small, the cavity is either almost circular in cross-section (Fig. 4) or slit-like, and occasionally multicystic. As a cavity extends it may track between the dorsal columns of white matter and become triangular in shape (Fig. 5). If the syrinx is large it may cause considerable damage to the posterior columns (Fig. 6). Alternatively it extends along the posterior horn of grey matter towards the dorsal root (Fig. 7).

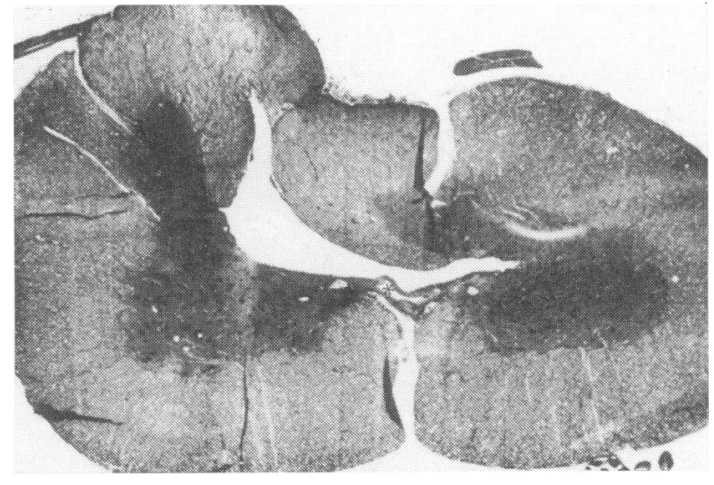

FIG. 8. T.S. cervical spinal cord of dog no. 4 showing collapse of the cord and a slit-like cavity dorsal to the central canal $(*)$ and extending into the posterior medium septum. $H$ and $E$ stain, $\times 8$.

When the cavity is large the cord may collapse after death and produce a syrinx very similar in shape to that seen in the human at post-mortem examination (Fig. 8).

EPENDYMA At most levels the ependyma remains intact and the central canal is not involved in the experimental syrinx (Figs 4, 7, and 8). But, at some levels in all the dogs the ependymal ring is broken and the central canal is in continuity with the syrinx (Figs 5 and 6). Occasionally the central canal is incorporated into the syringomyelic cavity and the ependymal lining is disrupted so that groups of ciliated ependymal cells are seen grouped as rosettes around blood vessels (Fig. 9).

In the examination of the five controls no level was found at which the central canal did not appear to be at least potentially patent, although it was most commonly partly collapsed.

TISSUE DAMAGE There is a variable amount of oedema in the white and grey matter around the cavities producing a spongy appearance within the tissue (Fig. 10). At several levels the lateral columns of grey matter show spongy changes even though they do not abut directly on to the syrinx. Evidence of white matter damage can be detected, especially around the larger cavities in the form of dense degenerating axons and lipid laden macrophages. Some chromatolytic neurones are seen in the anterior grey columns, again mainly related to the larger cavities.

Despite the tissue damage there is very little astrocytosis around the cavities. Few reactive astrocytes are seen and only occasional small areas of isomor- 


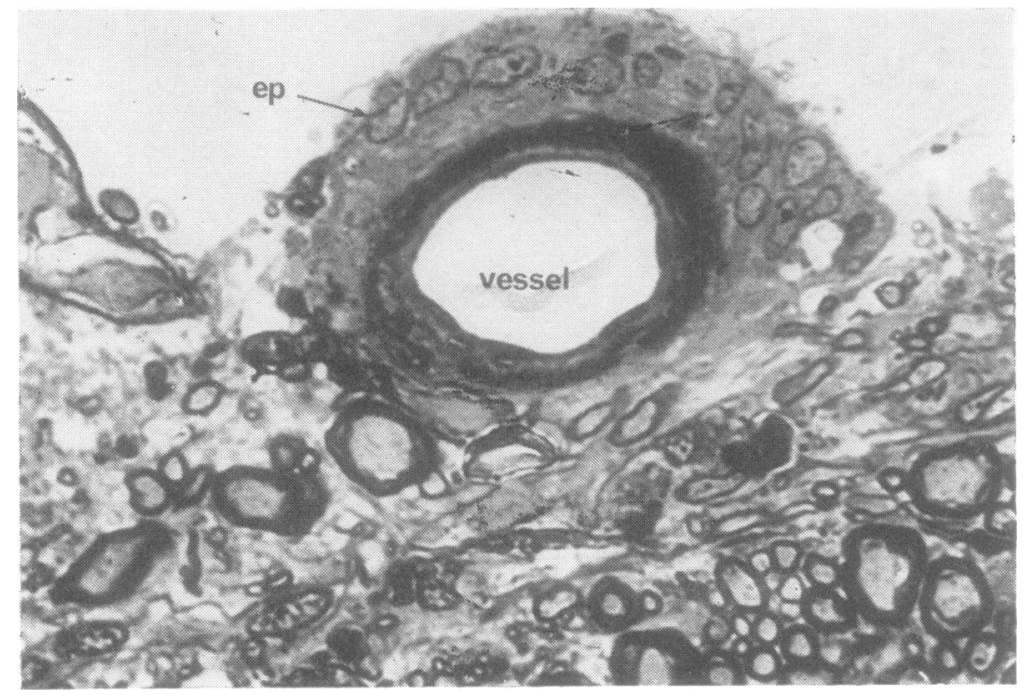

FIG. 9. T.S. spinal cord of dog no. 2 at T 6 segment. Part of the wall of a cavity showing a group of ependymal cells (ep) grouped around a blood vessel. One-micron Araldite section stained with toluidine blue, $\times 720$.

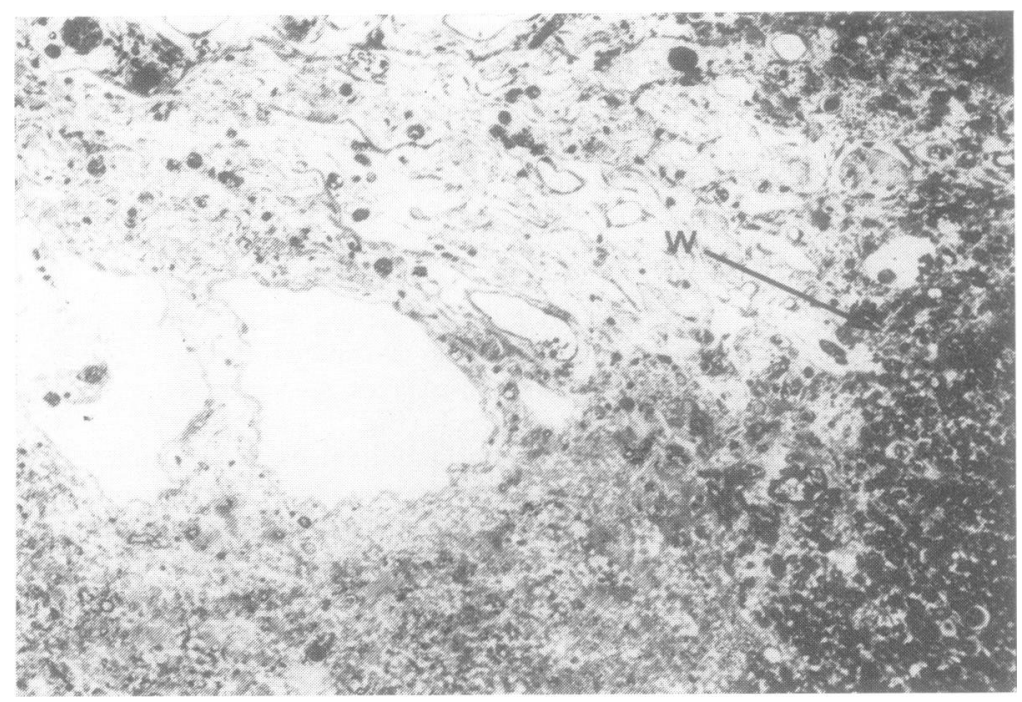

FIG. 10. T.S. upper thoracico spinal cord of dog no. 1. The $\vec{\omega}$ grey matter adjacent to the 흑 syrinx is cystic and spongy; some well-preserved white matter (W) is seen on the right. One-micron Araldite section stained with toluidine blue, $\times 120$.

phic gliosis can be detected (Fig. 11). The flattened cells that line the syringomyelic cavities appear to be astrocytes.

In one case, dog no. 4 , there is a moderate amount of chronic inflammation in the wall of the syrinx.

TISSUE REACTION AROUND CATHETER In each case there has been considerable scarring in the cord around the catheter. Figure 12 shows the fibrous collar composed of dense collagen around the site of the catheter. This reaction has developed over the four months that the catheter remained in the cord. In this particular animal, some damage to the posterior columns can be seen; this is probably a result of the insertion of the tube.

MEASUREMENT OF CONTROLS Sections of each segmental level of the four control cords were traced.

The periphery of the white matter $(\mathrm{Pw})$, the total $\mathrm{N}^{-}$ area of the cord (At) and the area of the grey matter 


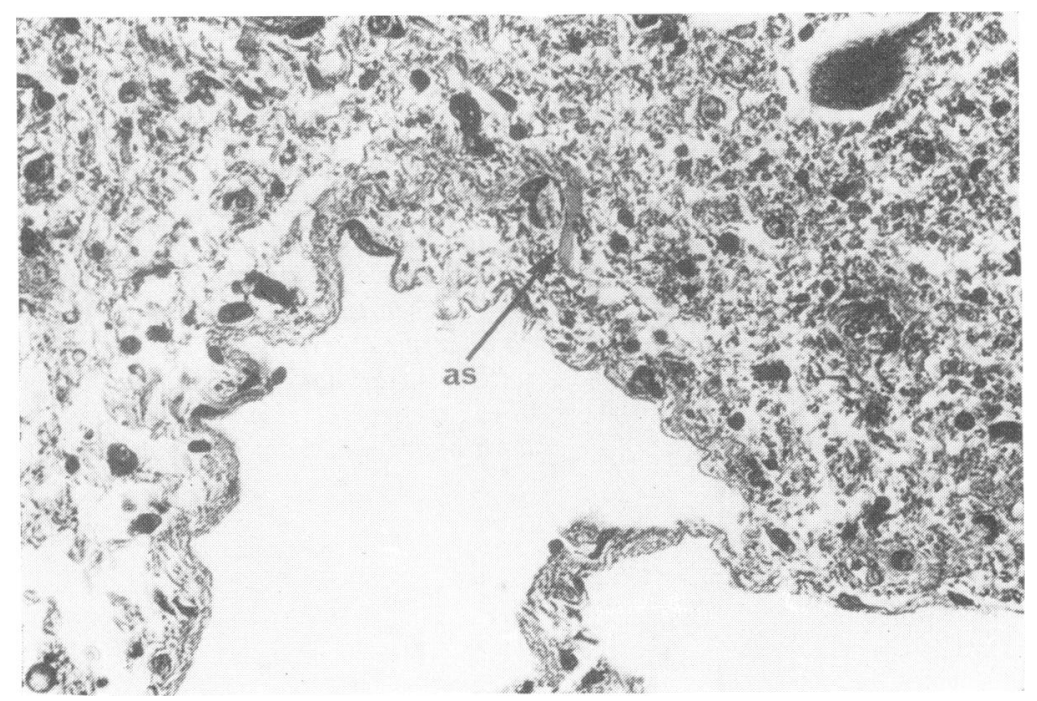

FIG. 11. T.S. upper thoracic spinal cord of dog no. 1 showing spongy and cystic grey matter in the wall of the syrinx but very little astrocytosis. One large fibrous astrocytic process is seen (as). $H$ and $E$ stain, $\times 120$.

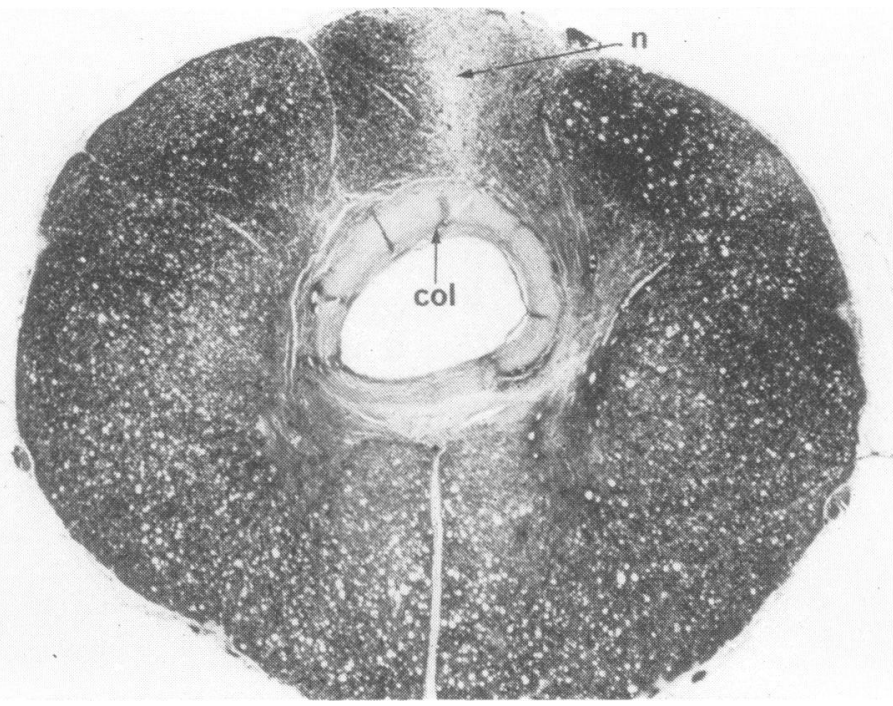

FIG. 12. T.S. spinal cord of dog no. 1 showing the thick collagenous collar (col) that has developed around the implanted catheter. Some damage to the posterior column is also noted (n). Loyez myelin stain, $\times 16$.

(Ag) were measured. The total peripheries and the ratio of the two areas were plotted for the controls and the results shown in Figs 13 and 14.

\section{DISCUSSION}

There seems to be no doubt that the injection of fluid into the implanted catheters caused this disease process. Although the beagles used in these experiments were from a strain prone to develop hydrocephalus, none of the five control dogs in this survey nor any of the cords examined from dogs used in other experiments were shown to have spontaneous syringomyelia, although our hydrocephalic control had a relatively large central canal. Hydrocephalus in dog no. 4 was associated with aqueduct stenosis and it prob- 


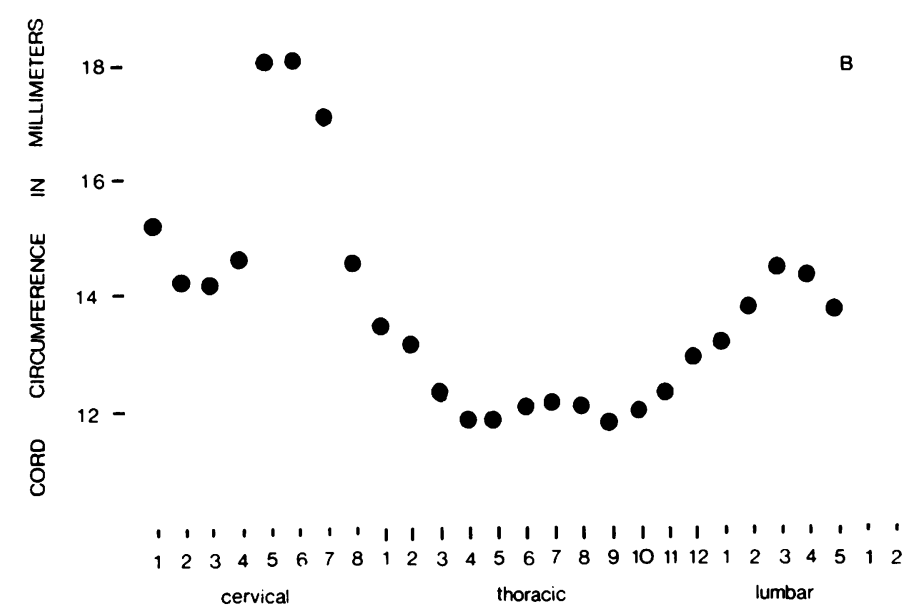

FIG. 13. The mean values for the cord circumference taken from five normal beagle dogs. The greatest circumference is seen to be at the fifth and sixth cervical vertebrae. (The segmental levels were taken at the point of emergence of the roots through the dura mater, not from the spinal cord.)

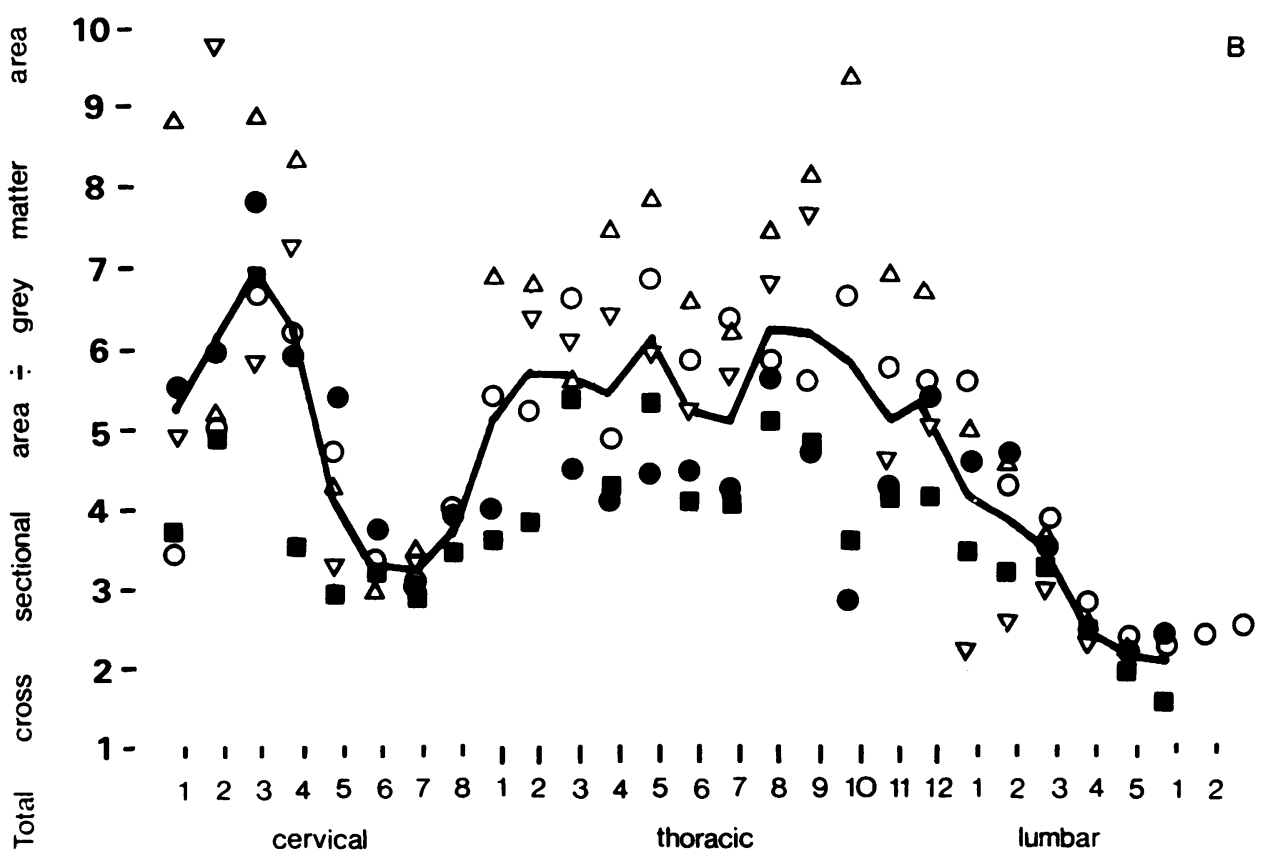

FIG. 14. All the values and the means for the ratio of the total cross-sectional area divided by grey matter area $(A T / A G)$. This demonstrates two sites of potential weakness, the $C 6 / 7$ region and also the lumbar region.

ably antedated the insertion of a catheter into the fourth ventricle.

The syringomyelic cavities that were formed after the infusion of saline or CSF into dog spinal cords showed a similar distribution to the lesions occurring in man.
The cervical region in the experimental dogs $\frac{7}{O}$ and in man appears to be more prone to develop syringomyelia than other regions of the cord. O The probable explanation for this predilection $N$ lies in the mechanical properties of the neural $\underset{\mathrm{C}}{N}$ tissues and the shape of the cord in this situation. 
The spinal cord approximates to a series of irregular concentric cylinders. The greatest strength probably lies in the pia mater around the outside. The white matter is stronger than grey (Ommaya, 1968) and forms the next concentric cylinder within the cord. Pressure within a cylinder exerts its greatest distending force where the surface area is greatest. In dealing with an irregular prism such as the cord, therefore, it is reasonable to look at the periphery of the cross-sectional area. Not only is the cord circumference relatively high in the cervical region (Fig. 13) but the ratio of grey matter to white matter is also high (Fig. 14). The relatively larger quantity of grey matter may be contributory to the vulnerability of the cervical region. The same factors apply to the lumbar enlargement which is also prone to syringomyelic cavities in humans and in our dog no. 4 (Fig. 3).

Fluid extends into the grey matter of the cord. It tracks along the posterior horns and between the posterior columns in the posterior median septum both in dogs and in man (Netsky, 1953; Ostertag, 1956). Fluid also tracks along these pathways in acute injuries to the cord as, for example, with gunshot wounds (Holmes, 1915) and it is probable that the route taken by the fluid is determined entirely by sites of mechanical weakness.

Ostertag (1956) proposed that syringomyelia involving the posterior columns of the cord was evidence of 'dysraphism'. However, the extension of the experimental syringes in our studies along the posterior median septum or along the posterior horn of grey matter suggests that these are merely paths of least resistance.

Several authors have suggested that cord cavitation and syringomyelia result from ischaemia due to involvement of meningeal vessels in adhesive arachnoiditis (Davison and Keschner, 1933; Mackay, 1939; Lubin, 1940; Nelson, 1943). Syringomyelia can in fact be produced experimentally by the injection of irritants such as kaolin into the cisternal subarachnoid space (Camus and Roussy, 1914; McLaurin, Bailey, Schurr, and Ingraham, 1954). The cord cavities in such animals extend beyond the segments affected by arachnoiditis. Becker, Wilson, and Watson (1972) have shown that similarly produced syringomyelia can be partly prevented in cats by plugging the central canal at the obex.
They suggest that the syringomyelia in their animals is due to disturbance of CSF flow in the region of the foramen magnum. Arachnoiditis at the foramen magnum is not uncommonly found in communicating syringomyelia (Appleby, Bradley, Foster, Hankinson, and Hudgson, 1969). In man, maldirection of CSF by arachnoid adhesions at the level of the lesion may be the basis of ascending syringomyelia associated with low spinal cord injury and paraplegia (Williams, 1970b). In the present experiments adhesive arachnoiditis was restricted to the area of catheter insertion and probably played no part in the formation of the cavities in the cord.

The possibility that syringomyelia results from vascular insufficiency independent of scarring of the meninges has been raised by several authors including Davison and Keschner (1933), Tauber and Langworthy (1935), and Netsky (1953) who observed thick-walled blood vessels closely associated with long-standing syringomyelic cavities in human spinal cords.

Some indication of the mechanisms of tissue damage in syringomyelia has come from the histological examination of the spinal cords in the present group of dogs. On first impression, the histology of the experimental lesion appears to differ considerably from that seen in human syringomyelia. The classical picture in the human of a cavity surrounded by a thick layer of isomorphic gliosis (Elsberg, 1916; Ostertag, 1956) is not seen in these dogs. But syringomyelia as observed post mortem in man has been established for many years, whereas in the dogs, the tissue changes are those of acute syringomyelia. When a patient with syringomyelia dies soon after extension of the cavity, the histological appearances are very similar to those seen in the present experiments; the surrounding tissue is spongy and oedematous rather than gliotic (Williams and Weller, 1972). The type and progression of tissue changes around a syringomyelic cavity closely resemble those observed in hydrocephalus. Blockage of the cerebral circulation of CSF in experimental animals causes dilatation of the ventricular system. In this situation the ependymal lining of the ventricular wall is disrupted and there is CSF oedema of the periventricular white matter (Weller, Wisniewski, Ishu, Shulman, and Terry, 1969; Milhorat, Clark, Hammock, and McGrath, 1970). Sub- 
sequently there is astrocytosis in the periventricular tissue both in experimental (Weller, Wisniewski, Shulman, and Terry, 1971) and human hydrocephalic brains (Russell, 1966; Weller and Shulman, 1972). It is probable that infusion of excessive amounts of fluid into the tissue is a major cause of damage in both hydrocephalus and syringomyelia and of the subsequent gliosis. There seems to be no basis for the emphasis which has often been placed upon gliosis as the cause of syringomyelia or to assume that the glial responses in this disease are abnormal.

Several hypotheses about the pathogenesis of syringomyelia centre around the relationship of the syrinx to the central canal and its ependymal lining. In the experimental dogs, the central canal was found to be completely separate from the syrinx in some instances, whereas in others it was confluent. The two situations may coexist in the same dog at different levels. The finding that connections may be present at several levels plus the certainty that the catheter was not implanted into the central canal lead to the conclusion that the central canal is not necessarily opened from within but that a cavity alongside the central canal may lay it open and distend it later. It is possible that in the second and third dogs, which tolerated relatively large injections of over $3 \mathrm{ml}$., the fluid escaped up the central canal and into the fourth ventricle. Lichtenstein (1949) believed that the fluid in syringomyelia was produced within the cord and it was by this route that he suggested the fluid escaped.

Another feature that has led to some confusion is the observation of groups, or nests of ependymal cells in human syringomyelia. These have been variously interpreted as embryonic cell nests (Worster-Drought, Wakeley, and Shafar, 1941) or as choroid plexus elements secreting fluid into the syrinx (Lichtenstein, 1949). Ependymal rosettes were found in the walls of the syringes in the present experimental animals and are very similar to the cerebral ependymal nests seen in experimental hydrocephalus in adult rabbits (Weller et al., 1969). In both cases the ependymal layer is probably disrupted mechanically and the separated groups of cells form rosettes around blood vessels.

The present series of experiments has shown that acute syringomyelia can be produced by the repeated infusion of fluid into the spinal cord.
One of the advantages of this experimental model is that the time sequence of the pathogenic processes involved is known. The histological appearances resemble acute syringomyelia and are similar to the tissue changes seen in acute hydrocephalus.

The results show that such an experimental model will be useful for physiological studies such as measuring energy transmission from the epidural veins to the syrinx via the subarachnoid space.

There is mounting evidence, mainly from clinical sources (Conway, 1967; Foster, Hudgson, and Pearce, 1969; Newton, 1969; Hankinson, 1970; Logue, 1971), to support Gardner's (1965) view of communicating syringomyelia. The present results also support his hypothesis. Furthermore, our findings agree with his contention that no useful distinction can be made between hydromyelia and syringomyelia.

Part of the difficulty in discussing the aetiology of syringomyelia seems to be that all the different mechanisms which produce an excess of flui $\vec{\Phi}$. within the spinal cord appear to produce a simp lar end result in terms of the sites of maximume destruction, extent of spread, and the type o tissue reactions. This supports the suggestio 8 that a common feature may be the infusion of fluid under pressure into neural tissue.

The suggestion is repeated that the term 'com= municating syringomyelia' would be useful to differentiate the commonly occurring form from other causes of intramedullary fluid under raised pressure which may dissect the central regions of the cord, such as fluid exuded from tumours, invasion by rapidly growing tumours, dissection by haematomyelia, and so on (Williams, 1970a).

Thanks are due to Reckitt and Coleman Ltd., Hull, for support during this research and to Mr. A. N. Guthkelch for suggestions during revision of the manuscript. Dr. Weller is now at the Department of Neuropathology, University Hospital, Southampton. Requests for reprints should be sent to Dr. Bernard Williams, Midland Centre for Neurosurgery and Neurology, Holly Lane, Warley, Worcestershire.

\section{REFERENCES}

Appleby, A., Bradley, W. G., Foster, J. B., Hankinson, J., and Hudgson, P. (1969). Syringomyelia due to chronic arachnoiditis at the foramen magnum. Journal of Neurological Science, 8, 451-464. 
Becker, D. P., Wilson, J. A., and Watson, G. W. (1972). The spinal cord central canal: response to experimental hydrocephalus and canal occlusion. Journal of Neurosurgery, 36, 416-424.

Camus, J., and Roussy, G. (1914). Cavités médullaires et méningites cervicales. Revue Neurologique, 27, 213-225.

Conway, L. W. (1967). Hydrodynamic studies in syringomyelia. Journal of Neurosurgery, 27, 501-514.

Davison, C., and Keschner, M. (1933). Myelitic and myelopathic lesions. 6. Cases with marked circulatory interference and a picture of syringomyelia. Archives of Neurology and Psychiatry, 30, 1074-1085.

Elsberg, C. A. (1916). Diagnosis and Treatment of Surgical Diseases of the Spinal Cord and its Membranes. Saunders: Philadelphia.

Foster, J. B., Hudgson, P., and Pearce, G. W. (1969). The association of syringomyelia and congenital cervicomedullary anomalies: pathological evidence. Brain, 92, 25-34.

Gardner, W. J., and Angel, J. (1958). The cause of syringomyelia and its surgical treatment. Cleveland Clinic Quarter$l y, 25,4-8$.

Gardner, W. J. (1965). Hydrodynamic mechanism of syringomyelia: its relationship to myelocele. Journal of Neurology, Neurosurgery, and Psychiatry, 28, 247-259.

Hankinson, J. (1970). Syringomyelia and the surgeon: In Modern Trends in Neurology, vol. 5, pp. 127-148. Edited by D. Williams. Butterworths: London.

Lich tenstein, B. W. (1949). Textbook of Neuropathology. Saunders: Philadelphia.

Logue, V. (1971). Syringomyelia: a radiodiagnostic and radiotherapeutic saga. Clinical Radiology, 22, 2-16.

Lubin, A. J. (1940). Adhesive spinal arachnoiditis as a cause of intramedullary cavitation. Archives of Neurology and Psychiatry, 44, 409-420.

Mackay, R. P. (1939). Chronic adhesive spinal arachnoiditis. A clinical and pathologic study. Journal of the American Medical Association, 112, 802-808.

McLaurin, R. L., Bailey, O. T., Schurr, P. H., and Ingraham, F. D. (1954). Myelomalacia and multiple cavitations of spinal cord secondary to adhesive arachnoiditis. Experimental study. Archives of Pathology, 57, 138-146.

Milhorat, T. H., Clark, R. G., Hammock, M. K., and McGrath, P. P. (1970). Structural, ultrastructural, and permeability changes in the ependyma and surrounding brain favouring equilibration in progressive hydrocephalus. Archives of Neurology, 22, 397-407.

Nelson, J. (1943). Intramedullary cavitation resulting from adhesive spinal arachnoiditis. Archives of Neurology and Psychiatry, 50, 1-7.

Netsky, M. G. (1953). Syringomyelia: a clinicopathologic study. Archives of Neurology and Psychiatry, 70, 741-777.

Newton, E. J. (1969). Syringomyelia as a manifestation of defective fourth ventricular drainage. Annals of the College of Surgeons of England, 44, 194-213.

Ollivier, C. P. (1827). Traité de la Moelle Épinière et de ses Maladies, 2 vol. $2 \mathrm{e}$ éditions. Crevot: Paris.

Ommaya, A. K. (1968). Mechanical properties of tissues of the nervous system. Journal of Biomechanics, 1, 127-138.

Ostertag, B. (1956). Dysrhapie und Syringomyelie. In Handbuch der speziellen Pathologien Anatomie und Histologie. Band 13, 4er Teil. Nervensystem, pp. 427-457. Edited by O. Lubarsch, F. Henke, and B. Rossle. Springer: Berlin.

Poser, C. M. (1956). The Relationship Between Syringomyelia and Neoplasm. Thomas: Springfield, Ill.

Russell, D. S. (1966). Observations on the Pathology of Hydrocephalus. Medical Research Council Special Report Series, No. 265. H.M.S.O.: London.

Tauber, E. S., and Langworthy, O. R. (1935). A study of syringomyelia and the formation of cavities in the spinal cord. Journal of Nervous and Mental Disease, 81, 245-264.

Weller, R. O., Wisniewski, H., Ishii, N., Shulman, K., and Terry, R. D. (1969). Brain tissue damage in hydrocephalus. Developmental Medicine and Child Neurology, Suppl. 20, 1-7.

Weller, R. O., Wisniewski, H., Shulman, K., and Terry, R. D. (1971). Experimental hydrocephalus in young dogs: histological and ultrastructural study of the brain tissue damage. Journal of Neuropathology and Neurology, 30, 613-626.

Weller, R. O., and Shulman, K. (1972). Infantile hydrocephalus: clinical, histological, and ultrastructural study of brain damage. Journal of Neurosurgery, 36, 255-265.

Williams, B. (1970a). Current concepts of syringomyelia. British Journal of Hospital Medicine, 4, 331-342.

Williams, B. (1970b). The distending force in the production of communicating syringomyelia. Lancet, 2, 41-42.

Williams, B., and Weller, R. O. (1972). Unpublished observations.

Worster-Drought, C., Wakeley, C. P. G., and Shafar, J. (1941). The surgical treatment of syringomyelia. British Journal of Surgery, 29, 56-73. 